\title{
Baseline Clinical Profile of a "Normal Population" of HIV Exposed Sero-Negative (HESN) Partners May Impact HIV Biomedical Prevention Studies Negatively
}

\author{
Pam Datong ${ }^{1,2^{*}}$, Evaezi Okpokoro ${ }^{3 * \#}$, Sophia Osawe ${ }^{2,3}$, Ruth Datiri ${ }^{2}$, Grace Choji ${ }^{2}$, \\ Felicia Okolo², Rebecca Abimiku², Ille Mamman²,3, Alash'le Abimiku ${ }^{2,3,4}$ \\ ${ }^{1}$ Plateau State Specialist Hospital, Jos, Nigeria \\ ${ }^{2}$ Plateau State Human Virology Research Centre, Jos, Nigeria \\ ${ }^{3}$ Institute of Human Virology, Abuja, Nigeria \\ ${ }^{4}$ Institute of Human Virology, University of Maryland School of Medicine, Baltimore, USA \\ Email:"evaezio@yahoo.com,"eokpokoro@ihvnigeria.org
}

Received 30 September 2015; accepted 27 November 2015; published 30 November 2015

Copyright (C) 2015 by authors and Scientific Research Publishing Inc.

This work is licensed under the Creative Commons Attribution International License (CC BY). http://creativecommons.org/licenses/by/4.0/

cC) (i) Open Access

\begin{abstract}
The burden and viral diversity of HIV in Nigeria makes it suitable to evaluate biomedical prevention strategies including HIV vaccines. We document baseline clinical characteristics of a cohort of HIV Exposed Sero-Negative (HESN) partners to highlight background morbidities that might impact the interpretation of research findings especially in low income countries where "normal control" is based on physical appearance and self-reporting. We established a 2-year prospective cohort of HESN, and obtained, at baseline medical history, general physical examination findings and safety laboratory tests results. Among 534 participants with a mean age of $37 \pm 9$ years, the commonest symptoms were headache $(25.5 \%)$ and fever $(20 \%)$, which occurred more among females. Also, 13\% reported a history of urethral/vaginal discharge and genital ulcer. High blood pressure (HBP) (i.e. blood pressure $\geq 140 / 90 \mathrm{mmhg}$ ) was a major abnormal examination finding, which occurred more among males $(53.2 \%$ vs $26.2 \%, p<0.01)$. More female participants had abnormal laboratory results with $31 \%$ having low hemoglobin concentration $(<12 \mathrm{~g} / \mathrm{dl}, p=0.021)$; $30 \%$ with elevated alanine transaminase level $(p=0.019)$ and $28 \%$ with abnormal blood urea nitrogen level $(p=0.093)$. HBP and abnormal safety laboratory are significant findings among so called "normal population" that could affect interpretation of research findings of HIV biomedical prevention studies in Nigeria.
\end{abstract}

\footnotetext{
Both are first authors.
}

"Corresponding author.

How to cite this paper: Datong, P., Okpokoro, E., Osawe, S., Datiri, R., Choji, G., Okolo, F., Abimiku, R., Mamman, I. and Abimiku, A. (2015) Baseline Clinical Profile of a "Normal Population" of HIV Exposed Sero-Negative (HESN) Partners May Impact HIV Biomedical Prevention Studies Negatively. World Journal of AIDS, 5, 299-307. 
Keywords

Clinical Characteristics, Discordant Couple, Developing Country, HIV Vaccine Trial, Nigeria

\section{Introduction}

Nigeria remains one of the countries severely affected by HIV/AIDS. An estimated 281,180 new infections were reported in 2011 and over $80 \%$ of these were through heterosexual sex transmission [1]. Several interventions have successfully reduced the transmission rate but are unable to completely stem the pandemic. Some of the successful interventions are: public awareness through campaigns and counseling on the dynamics and risks of transmission and the need for consistent and correct condom use to reduce the spread of infection. Availability of highly active anti-retroviral therapy has reduced infectivity of HIV-infected individuals to others [2] [3], but low condom use [4] [5], issues of accessibility and compliance to ARV have compromised this gain. Therefore, combining multiple biomedical HIV preventive approaches including preventive vaccines along with these interventions are imperative to turn the tide on the HIV pandemic.

Treatment with ARV for prevention (TasP) of HIV-infected persons reduced infection to their HIV-Uninfected partners by 96\% [2] [3] and between 62\% and 73\% HIV-1 infections were averted by ARV when used as pre-exposure prophylaxis (PrEP) in Africans [6]. RV144, the Thai vaccine trial demonstrated the first evidence that a safe and effective HIV preventive vaccine is possible in humans by lowering the rate of HIV infection by 31.2\% [7]. To date no vaccine trial has been conducted in Nigeria despite the identification of HIV subtypes G and CRF02A/G as the predominant drivers of the epidemic in Nigeria and the rest of West Africa [8].

Considering that heterosexual route is the commonest route of transmission in Sub Saharan Africa, HIV-1 Exposed Sero Negative (HESN) partners in a discordant relationship are natural models to study biomedical prevention methods including vaccines. This population remains exposed to HIV transmission despite WHO recommendation to initiate ARTs irrespective of CD4 count for the HIV positive partner [9].

However understanding the baseline clinical and laboratory characteristics of a "normal" HESN population in Nigeria is the key to reducing unnecessary exclusion of trial volunteers [10], conducting, assessing comparability between treatments arms [11] [12] (i.e. after randomization) and contextualizing results of HIV biomedical prevention studies among this population. In addition, safety and efficacy of therapeutic or preventive HIV vaccine trials are often measured by monitoring changes to baseline findings [13] and yet a number of clinical trials in developing countries enroll a "normal" population based on self-reported questionnaire with little clinical and laboratory tests to confirm volunteers information. Our study intends to show that a significant number of individuals that work through the door as "normal" have a number of abnormal laboratory and clinical readings that they themselves are not aware of. In this respect being aware of the frequent abnormalities in a population has the potential of interpreting results from clinical trials more accurately.

Toward this end, we documented the demographics, clinical and laboratory characteristics of a population of "normal" HESN of a sero-discordant couple in north central Nigeria who considered themselves "normal" as an important first step to HIV biomedical prevention studies including a preventive HIV-1 vaccine among this population.

\section{Method}

A prospective cohort study was conducted at Plateau State Human Virology Research Center (PLASVIREC) Jos and 4 satellite sites (i.e. Church Of Christ In Nigeria (COCIN), Mangu; Abubakar Balewa Uinversity Teaching Hospital (ABUTH), Bauchi; Dalhatu Araf Specialist Hospital (DASH), Lafia and Federal Medical Center, Keffi (FMCK)) located around Jos, Nigeria as part of a vaccine preparedness study. Ethical clearance was obtained from the Plateau State Specialist Hospital (PSSH) ethics committee, the National Health Research Ethics Committee of Nigeria (NHREC), and the University of Maryland, Medical School ethics committee. Participants were recruited from the community and from the HESN database maintained at the counseling center. Following detailed explanation to each eligible participant in an established discordant relationship of at least 3 months, written informed consent was obtained and participants were enrolled in the study with a 2 years follow up. A semi-closed interviewer based questionnaire was administered after which risk behavior, clinical symptoms of 
acute HIV infections, comorbidities as well as common endemic infections like malaria were documented; accompanied by a detailed general and physical examination. History of STI was obtained using the WHO template for syndromic management of STI during a total of 10 follow up visits. The first three visits were monthly and subsequent visits were quarterly.

\subsection{Medical History}

During each study visit, experienced medical personnel obtained medical history of fever, headache, nausea/vomiting, diarrhea, sore throat, easy fatigue ability, cough or difficult breathing over the previous 3 months from the HESN enrollees to establish or exclude any concurrent illness or common endemic infections like malaria, acute respiratory infections and diarrhea. History of Tuberculosis was obtained from participants using the National Tuberculosis control program guideline for screening of TB suspects (i.e. persistent cough for two weeks or more and one of the following: weight loss, tiredness, fever, chest pain, coughing up blood, shortness of breath and loss of appetite).

\subsection{Physical Examination}

A careful general examination was performed for pallor, jaundice, cyanosis, finger clubbing, facial or pedal edema, generalized skin lesion, palpable lymph nodes and measured body temperature and weight. Blood pressure (BP) was measured with an automated BP monitor Homemed KD-591 using a cuff covering 2/3 of the nondominant upper arm while sitting. High blood pressure (HBP) was defined as systolic blood pressure $>140$ $\mathrm{mmHg}$ and/or diastolic blood pressure $>90 \mathrm{mmHg}$. Any high reading was repeated after 5 minutes and the average of the 2 readings recorded. Abdominal examination was done for any abdominal scars or pain, palpable liver or spleen. A pelvic examination was performed only when a participant presented with a history of urethral or vaginal discharge, genital ulcers or warts, painful inguinal lymph nodes and lower abdominal pain in females.

\subsection{Treatment and Referral System}

Participants who presented with minor ailments were treated by study physicians while those with an elevated BP were counseled on life style modification (quitting smoking, reduced alcohol intake, low fat and salt diet, increase physical activity and maintaining a healthy weight) and referred to their primary care giver. Those who reported any symptom of STI or that required advance medical care were promptly referred to appropriate clinics within the study sites where possible.

\subsection{Safety Laboratory Tests}

A complete blood count (CBC) and differential on blood samples were performed using Sysmex Kx-21N from Sysmex corporation Kobe, Japan and serum samples were analyzed for liver and kidney functions tests using Vitros 350 fully automated chemistry analyzer from Ortho-clinical Diagnostics, USA during each study visits. Other laboratory investigations performed include serology for HIV, Syphilis and Hepatitis C. Dried blood spots was obtained for storage. The supporting reference laboratory in Jos generated local normal values (i.e. standard reference values) that was used for participants in the study [14].

\subsection{Statistical Analysis}

Considering that sex is an effect modifier, the study data was segregated and analyzed by sex. Continuous variables were assessed for normality and described using appropriate descriptive statistics (i.e. mean or median, interquartile range, standard deviation). Abnormal laboratory test results were defined as values that were not within the reference range for each laboratory test (i.e. below or above the reference range) as obtained from PLASVIREC (national reference laboratory). The frequency of abnormal laboratory tests were measured and presented in tables. Binary outcomes such clinical features were assessed as proportion and Pearson Chi sq or Fishers exact test were used where appropriate.

\section{Results}

A total of 660 "normal” HESN in a discordant relationship were screened and 540 (82\%) eligible participants 
who consented, enrolled for the study. Among these, six participants were terminated following a positive HIV serology result at baseline. Consequently 534 (81\%) consented participants were eligible for follow up. 205 (38\%) of participants were enrolled from the PLASVIREC, Jos (the study coordinating center) while the others were from 4 satellite sites bordering Jos (i.e. located at Mangu, Bauchi; Keffi and Lafia).

\subsection{Socio-Demographic}

There were 1.1:1 male to female ratio (278 vs 256) among study participants (Table 1).

The mean age of all participants was $37 \pm 9$ years with a range of 20 - 65 years and female participants were 5 years younger ( $35 \pm 8$ years vs $40 \pm 9$ years; $p<0.01$ ). All study participants were in a marital relationship and had been sero-discordant for less than 1 year to 10years though 79\% (424/534); had been in this sero-discordant relationship for at least 1 year. Majority (89\%, 475/534) had some formal education (i.e. primary, secondary and tertiary), and 76\% (408/534) practiced Christianity.

Table 1. Baseline socio-demographic characteristics of 534 HESN from a HIV sero-discordant cohort.

\begin{tabular}{|c|c|c|c|c|c|}
\hline \multicolumn{2}{|c|}{ Characteristics } & Male N = 278 (\%) & Female N = $256(\%)$ & Total N = 534(\%) & $p$-values \\
\hline \multicolumn{2}{|c|}{ Age (years) Mean \pm SD } & $40 \pm 9$ & $35 \pm 8$ & $37 \pm 9$ & $<0.01$ \\
\hline \multirow[t]{4}{*}{ Age group } & $20-30$ & $46(16.6)$ & $90(32.4)$ & $136(25.5)$ & \\
\hline & $31-40$ & $123(44.2)$ & $113(44.1)$ & $236(44.2)$ & \\
\hline & $41-50$ & $70(25.2)$ & $48(17.3)$ & $118(22.1)$ & \\
\hline & $>50$ & $39(14)$ & $5(2)$ & $44(08)$. & \\
\hline \multicolumn{6}{|l|}{ Education } \\
\hline & None & $15(5.4)$ & $44(17.2)$ & 59 (11.1) & \\
\hline & Primary & 57 (20.5) & $80(31.3)$ & $137(25.6)$ & \\
\hline & Secondary & 79 (28.3) & $81(31.6)$ & $160(30)$ & \\
\hline & Tertiary & $127(45.7)$ & 51 (19.9) & $178(33.3)$ & \\
\hline \multicolumn{6}{|l|}{ Marital status } \\
\hline & Married & $278(100)$ & $256(100)$ & $534(100 \%)$ & \\
\hline \multicolumn{6}{|c|}{ Religion } \\
\hline & Christianity & $218(78.4)$ & $190(74.2)$ & $408(76.4)$ & \\
\hline & Muslim & $60(21.6)$ & $66(25.8)$ & $126(23.6)$ & \\
\hline Employed & Yes & $180(64.8)$ & $72(28.2)$ & $252(47.2)$ & \\
\hline \multicolumn{6}{|c|}{ Duration in sero-discordant relationship (years) } \\
\hline & $<1$ & $65(23.4)$ & $45(17.6)$ & $110(20.6)$ & \\
\hline & $1-5$ & $166(59.7)$ & $175(68.4)$ & $341(63.9)$ & \\
\hline & $6-10$ & $44(15.9)$ & 35 (13.7) & $79(14.8)$ & \\
\hline & $>10$ & $3(1.1)$ & $1(0.4)$ & $4(0.8)$ & \\
\hline \multicolumn{6}{|c|}{ Enrollment site } \\
\hline & PLASVIREC Jos & $115(41.4)$ & $90(35.2)$ & $205(38.4)$ & \\
\hline & COCIN Mangu & $21(07.6)$ & $51(19.9)$ & $72(13.5)$ & \\
\hline & ATBUTH Bauchi & $41(14.8)$ & $40(15.7)$ & $81(15.2)$ & \\
\hline & FMC-Keffi & $23(8.3)$ & $16(6.3)$ & $39(7.3)$ & \\
\hline \multicolumn{2}{|c|}{ DASH Lafia } & $78(28.1)$ & $59(23.1)$ & $137(25.6)$ & \\
\hline
\end{tabular}


Table 2. Clinical profile at baseline showing frequency of occurrence of common clinical symptoms and signs.

\begin{tabular}{|c|c|c|c|c|c|}
\hline Baseline clinical symptoms and signs & Male N = $278(\%)$ & Female $N=256(\%)$ & Overall $N=534(\%)$ & Risk ratio* & $p$-value \\
\hline Fever & $43(15.5)$ & $64(25)$ & $107(20.0 \%)$ & 0.62 & $<0.01$ \\
\hline Headache & 47 (16.9) & $90(35.2)$ & 137 (25.6\%) & 0.48 & $<0.01$ \\
\hline Diarrhea & $5(1.8)$ & $10(3.9)$ & $15(2.8 \%)$ & 0.46 & 0.13 \\
\hline Fatigue & $11(3.9)$ & $14(5.5)$ & $25(4.7 \%)$ & 0.71 & 0.38 \\
\hline Sore throat & $9(3.2)$ & $11(4.3)$ & $20(3.7 \%)$ & 0.74 & 0.49 \\
\hline Nausea & $1(0.4)$ & $13(5.1)$ & $14(2.6 \%)$ & 0.07 & $<0.01$ \\
\hline Muscle pain & $19(6.8)$ & $14(5.5)$ & $33(6.18 \%)$ & 1.24 & 0.51 \\
\hline Joint pain & $20(7.2)$ & $24(9.4)$ & $44(8.2 \%)$ & 0.76 & 0.32 \\
\hline Skin lesions & $4(1.4)$ & $6(2.3)$ & 10 (1.9\%) & 0.61 & 0.42 \\
\hline Cough & $9(3.2)$ & $7(2.7)$ & $16(3.0 \%)$ & 1.19 & 0.78 \\
\hline Night sweats & $6(2.2)$ & $6(2.3)$ & $12(2.2 \%)$ & 0.96 & 0.85 \\
\hline Urethral discharge & $9(3.2)$ & NA & - & - & - \\
\hline Vaginal discharge & NA & $54(21.1)$ & - & - & - \\
\hline Lower abdominal pains & NA & $25(9.8)$ & - & - & - \\
\hline Genital ulcer & $4(1.4)$ & $4(1.6)$ & $8(1.5)$ & 0.88 & 0.88 \\
\hline Body Mass Index (BMI) & & & & - & \\
\hline Underweight $(<18.5)$ & $11(4)$ & $10(4)$ & $20(3.9)$ & & 0.98 \\
\hline Normal (18.5 - 24.9) & $156(56.1)$ & $112(43.8)$ & $268(50.2)$ & & $<0.01$ \\
\hline Overweight (25 - 29.9) & $86(30.1)$ & $74(28.9)$ & $160(30)$ & & 0.73 \\
\hline Obese $(\geq 30)$ & $24(8.6)$ & $57(22.3)$ & $81(15.2)$ & & $<0.01$ \\
\hline Raised temperature $\left(\geq 37.2^{\circ} \mathrm{C}\right)$ & $8(2.9)$ & $11(4.3)$ & $19(3.6)$ & 0.67 & 0.35 \\
\hline $\begin{array}{c}\text { High blood pressure } \\
\text { (BP systolic } \geq 140 \text { and/or diastolic } \geq 90 \text { ) }\end{array}$ & $148(53.2)$ & $67(26.2)$ & $215(40.3)$ & 2.03 & $<0.01$ \\
\hline
\end{tabular}

\subsection{Clinical Features}

Overall, a history of headache (25.5\%) and fever (20\%) were the commonest complain reported at enrollment (i.e. baseline) by 137 and 107 study participants' respectively. When segregated by sex; clinical symptoms such as headache, fever and nausea were significantly less common among males when compared to the females (Table 2).

Understandably, 15.5\% (83/534) of study participants reported to have received treatment for malaria. Using the WHO template for assessing sexually transmitted infections, urethral discharge was reported by $3.2 \%(9 / 278)$ of male participants as against $21 \%$ (54/256) of female participants that reported vaginal discharge. On physical examinations, elevated blood pressure (i.e. blood pressure $\geq 140 / 90 \mathrm{mmhg}$ ) was the most prevalent abnormal physical findings recorded in $40.3 \%$ (215/534) participants and was significantly commoner among males $(53.2 \%$ vs $26.2 \%, p<0.01)$. Conversely, obesity (BMI $\left.\geq 30 \mathrm{~kg} / \mathrm{m}^{2}\right)$ was significantly commoner among female $(22.3 \%$ vs $8.6 \%, p<0.01$ ).

\subsection{Safety Laboratory}

Eight safety laboratory tests (i.e. hemoglobin concentration; white blood cell count; platelet count; total bilirubin; aspartate transaminase; alanine transaminase; blood urea nitrogen and creatinine levels) done at enrollment are presented on Table 3. 
Table 3. Safety laboratory tests results segregated by sex.

\begin{tabular}{|c|c|c|c|c|c|c|c|c|c|}
\hline $\begin{array}{l}\text { Subject } \\
\text { group }\end{array}$ & Parameters & $\begin{array}{c}\text { Hemoglobin } \\
\text { concentration } \\
\text { (g/dl) }\end{array}$ & $\begin{array}{c}\text { White } \\
\text { blood cells } \\
\left(10^{9} / 1\right)\end{array}$ & $\begin{array}{c}\text { Platelets } \\
\left(10^{9} 1\right)\end{array}$ & $\begin{array}{c}\text { Total } \\
\text { bilirubin } \\
(\mu \mathrm{mol} / \mathrm{l})\end{array}$ & $\begin{array}{c}\text { Aspartate } \\
\text { transferase } \\
\text { (iu/l) }\end{array}$ & $\begin{array}{c}\text { Alanine } \\
\text { transaminase } \\
\text { (iu/l) }\end{array}$ & $\underset{(\mathrm{mmol} / \mathrm{l})}{\text { Urea }}$ & $\begin{array}{c}\text { Creatinine } \\
(\mu \mathrm{mol} / \mathrm{l})\end{array}$ \\
\hline \multirow[t]{3}{*}{$\begin{array}{c}\text { Male } \\
(\mathrm{N}=278)\end{array}$} & Mean & 14.1 & 4.7 & 216 & 10.7 & 31.6 & 27.4 & 3.3 & 75.7 \\
\hline & $\begin{array}{c}\text { Standard } \\
\text { reference range }\end{array}$ & $13-18$ & $3.5-11$ & $130-400$ & $0-17$ & $17-59$ & $10-55$ & $2.9-8.9$ & 60 - 118 \\
\hline & $\begin{array}{l}\text { Proportion of male } \\
\text { results outside } \\
\text { reference range in \%(n) }\end{array}$ & $17 \%(46)$ & $8 \%(23)$ & $8 \%(21)$ & $17 \%(46)$ & $11 \%(31)$ & $16 \%(44)$ & $18 \%(50)$ & $11 \%(30)$ \\
\hline \multirow[t]{3}{*}{$\begin{array}{c}{ }^{*} \text { Female } \\
(\mathrm{N}=256)\end{array}$} & Mean & 12.5 & 5.2 & 251 & 8.7 & 25.5 & 23.4 & 3.2 & 64.9 \\
\hline & $\begin{array}{c}\text { Standard } \\
\text { reference range }\end{array}$ & $12-16$ & $3.5-11$ & $130-400$ & $0-17$ & $14-36$ & $7-30$ & $2.9-8.9$ & $50-98$ \\
\hline & $\begin{array}{l}\text { Proportion of female } \\
\text { results outside } \\
\text { reference range in \%(n) }\end{array}$ & $30 \%$ (77) & $6 \%(15)$ & $8 \%(20)$ & $7 \%(17)$ & $19 \%(48)$ & 29\% (73) & $28 \%(72)$ & $9 \%(22)$ \\
\hline $\begin{array}{l}\text { Risk } \\
\text { ratio }\end{array}$ & $\begin{array}{l}\text { Proportion of male } \\
\text { with abnormal } \\
\text { result to female with } \\
\text { abnormal result }\end{array}$ & 0.54 & 1.34 & 1 & 2.42 & 0.63 & 0.53 & 0.64 & 1.67 \\
\hline $\begin{array}{c}\text { "Pearson } \\
\text { Chi2 }\end{array}$ & $p$-value & 0.021 & 0.566 & 1 & 0.029 & 0.17 & 0.019 & 0.093 & 0.192 \\
\hline
\end{tabular}

${ }^{*}$ Female is the reference group. ${ }^{\#} \mathrm{Chi} 2$ value for the comparison between proportions of male with out of reference range results compared to female with out of reference range results. Relevant findings.

These test result were segregated by sex as some laboratory reference values differ significantly between males and females. The mean hemoglobin concentration was $14.4 \mathrm{~g} / \mathrm{dl}$ among male and was $12.5 \mathrm{~g} / \mathrm{dl}$ among female participants. In addition, more females had hemoglobin concentration that was below the standard reference range ( $31 \%$ vs $17 \%, p=0.021)$. Similarly, $30 \%$ female compared to $16 \%$ males had significantly deranged alanine transaminase level $(p=0.019)$ and $28 \%$ female vs $18 \%$ male had significantly deranged blood urea nitrogen level $(p=0.029)$.

\section{Discussion}

We present baseline clinical and laboratory characteristics of presumably 'normal and/or healthy' HIV Exposed Sero Negative (HESN) partners enrolled in a HIV vaccine preparedness study in Jos Nigeria. Our findings highlight potential confounders that may be relevant in the randomization and interpretation in any clinical trial [15] especially in populations in LMIC. Our study cohort, unlike other HESN studies [16] [17] had a balanced male to female ratio (1.1:1), which makes our findings relevant to the general population. Headache, fever or internal heat, fatigue and muscle/joint aches were common complains in our cohort, which is not surprising for a malaria endemic region as this. Importantly, these symptoms complicate enrollment, as these symptoms are similar to those of acute HIV infection: studies planned in such populations must take this potential complication into consideration. Fever is one of the commonest reported symptoms (107/534, 20\%) of the participants but elevated body temperatures were only documented in (19/534, 3.56\%) supporting the fact that some of these presentations were likely psychosomatic or antipyretic medications might have been taken prior to presentation to the clinic. However, our finding is lower than the $46.6 \%$ reported symptom of fever found among market traders [18] and $29 \%$ reported among elderly population in Nigeria [19]. This highlights the need for proper diagnosis of malaria before treatment especially in a population to be involved in HIV prevention study trials, as any of the participants may have acute HIV infection and be misdiagnosed as malaria. The introduction of malaria prevention strategies such as Insecticide treated nets, insecticides, and prophylaxis may be useful for any cohort involved in HIV biomedical prevention trials to limit the complains and complications of malaria. In addition psychosomatism, a very common presentation of outpatient attendees in developing countries, could mimic such 
non-specific complains [20].

Women remain more at risk of sexual transmitted infections as vaginal discharge (54/256, 21.1\%) and lower abdominal pains (25/256, 9.8\%) were more common complains when compared with urethral discharge (9/278, $3.2 \%$ ) in men in this cohort. Although it is not as high as that reported among high-risk groups like female sex workers in Nigeria [21] and in a Mexican City [22] our findings in women is higher than the $3.2 \%$ reported among market trader [18] (i.e. general public) in Nigeria. This places HESN as a medium risk population for HIV acquisition. .

Interestingly high blood pressure (systolic $\geq 140 \mathrm{mmhg}$ and/or diastolic $\geq 90 \mathrm{mmhg}$ ) was reported in a significant number $(215 / 534,40.3 \%)$ of our participants. This reflects the rising trend of non-communicable diseases including hypertension in Nigeria. Other studies have reported a range of $8 \%$ to $46.4 \%$ with a pooled national average of $22.5 \%$ [23] [24] so the $40.3 \%$ reported in our cohort is much higher than the national average and the reason for that is not exactly clear. Importantly for biomedical clinical trials, these individuals were unaware of the high blood pressure and had considered themselves healthy. As informal caregiver to an HIV+ partner, the HESN could be stressed or even depressed [25] or anxious which might be responsible for the increased high blood pressure [26] among HESN. It is not completely clear why men were twice at risk of having high blood pressure than women despite the finding that less male participants were obese. It is possible that women were more willing to get help and support in dealing with a HIV+ partner than men were. The male participants were slightly more elderly.

There was significantly difference in hematological and clinical chemistry results between males and females (Table 3). A similar study conducted on "normal" Nigerian adult populace also documented statistically significant differences in hematological and clinical chemistry parameters between males and females [14]. In our study, males were $46 \%$ less likely to have hemoglobin concentration below the standard reference range values (i.e. anemia; $p=0.021$ ) compared with females (Table 3). Physiologic difference such as short interval deliveries [27] among females and menstrual bleeding could explain this difference. Generally, nutritional deficiency with iron deficiency or in combination with megaloblastic anemia is the singular most common cause of bone marrow malfunction resulting to anemia (HB $<11 \mathrm{~g} / \mathrm{dl})$ and depressed production of other blood cells [27]. In populations of LMIC, anemia is further compounded by endemic malaria and neglected tropical diseases such as hook worm infestation. Similarly, males in our study were $47 \%$ less likely to have alanine transaminase levels that were outside standard reference range when compared to female ( $16 \%$ vs $29 \%, p=0.019$; Table 3 ). This is contrary to our expectation of a positive correlation between alanine transaminase and higher hemoglobin concentration among males [28]. Moreover males were more prone to alcoholic drinks which could lead to such elevation or derangement. Therefore, this unexpected finding of elevated (deranged) levels of alanine transaminase being commoner among females may be associated with having more obese females [29] in our study.

Hepatitis C test result was similar for both male and female (8\% vs $7 \%$; as reported in a separate manuscript). In addition, males were twice as likely to have deranged total bilirubin level; a corresponding liver enzyme that should be elevated in hepatitis ( $17 \%$ vs $7 \%, p=0.029)$.

The higher number of female participants (i.e. 28\%) who presented with deranged blood urea nitrogen when compared to male participants ( $28 \%$ vs $18 \%, p=0.093$; Table 3 ) is also contrary to our expectation as more males presented with elevated blood pressure which should impact negatively on renal function over time. Hence, a creatinine clearance for the renal status of the participants would need to be carried out in future studies. Other factors such as dehydration should be checked as well.

In summary findings from our study underscore the need to use clinical and laboratory tests to fully characterize the baseline clinical profile of so-called "normal" populations in Africa prior to initiating a clinical trial in this population as our data show that a number of the clinical and laboratory monitoring parameters are anything but normal. Moreover a significant number of the volunteers were not aware that they had high blood pressure or abnormal hematological and chemistry values.

\section{Conclusion}

Our study highlights: history of fever, headache, blood pressure $>140 / 90 \mathrm{mmhg}$, anemia and deranged safety laboratory results especially among "normal" females as significant findings that could affect exclusion/inclusion criteria at enrollment, and affect interpretation of clinical trials results including the comparability of study arms. These findings are critical for the preparation for future HIV biomedical prevention studies in Nigeria. 


\section{Acknowledgements}

Global Health Research Initiative (GHRI), a research funding partnership composed of the Canadian Institutes of Health Research, the Canadian International Development Agency, and the International Development Research Centre, funded this work. We also acknowledge the contributions of the satellite sites and PLASVIREC study staff. Finally, we thank the volunteers for their contribution and valuable time to the study.

\section{Authors Disclosure Statement}

No competing financial interest exists.

\section{References}

[1] NACA (2011) Fact Sheet: Update on the HIV/AIDS Epidemic and Response in Nigeria. NACA, Boston.

[2] Cohen, M.S., et al. (2011) Prevention of HIV-1 Infection with Early Antiretroviral Therapy. New England Journal of Medicine, 365, 493-505. http://dx.doi.org/10.1056/NEJMoa1105243

[3] Vermund, S.H. (2013) Treatment as Prevention for HIV in China. Lancet, 382, 1159-1161. http://dx.doi.org/10.1016/S0140-6736(12)62005-4

[4] Reynolds, S.J., et al. (2011) HIV-1 Transmission among HIV-1 Discordant Couples before and after the Introduction of Antiretroviral Therapy. AIDS, 25, 473-477. http://dx.doi.org/10.1097/QAD.0b013e3283437c2b

[5] Huachun, Z., et al. (2012) Condom Use in China: Prevalence, Policies, Issues and Barriers. Sexual Health, 9, 27-33. http://dx.doi.org/10.1071/SH11021

[6] Baeten, J.M., et al. (2012) Antiretroviral Pre-Exposure Prophylaxis for HIV-1 Prevention among Heterosexual African Men and Women. New England Journal of Medicine, 367, 399-410. http://dx.doi.org/10.1056/NEJMoa1108524

[7] Rerks-Ngam, S., Pitisuttithum, P. and Nitayaphan, S. (2009) Vaccination with ALVAC and AIDSvax to Prevent HIV-1 Infection in Thailand. New England Journal of Medicine, 361, 2209-2220. http://dx.doi.org/10.1056/NEJMoa0908492

[8] Abimiku, A.G., et al. (1994) Subgroup G HIV Type 1 Isolates from Nigeria. Research and Human Retroviruses. Research and Human Retroviruses, 10, 1581-1583. http://dx.doi.org/10.1089/aid.1994.10.1581

[9] WHO (2012) Guidance on Couples HIV Testing and Counselling Including Antiretroviral Therapy for Treatment and Prevention in Serodiscordant Couples. Recommendations for a Public Health Approach, World Health Organization, Geneva.

[10] Omosa-Manyonyi, G.S., et al. (2011) Reasons for Ineligibility in Phase 1 and 2A HIV Vaccine Clinical Trials at Kenya Aids Vaccine Initiative (KAVI), Kenya. PLoS ONE, 6, e14580. http://dx.doi.org/10.1371/journal.pone.0014580

[11] Altman, D. and Doré, C. (1990) Randomisation and Baseline Comparisons in Clinical Trials. The Lancet, 335, $149-153$. http://dx.doi.org/10.1016/0140-6736(90)90014-V

[12] Peduzzi, P., Henderson, W., Hartigan, P. and Lavori, P. (2002) Analysis of Randomized Controlled Trials. Epidemioloic Reviews, 24, 26-38.

[13] UT Health (2008) Clinical Trials Resource Center. Clinical Trials Glossary 2008. https://www.uth.edu/ctrc/participants/glossary.htm

[14] Miri-Dashe, T., Osawe, S., Tokdung, M., et al. (2014) Comprehensive Reference Ranges for Hematology and Clinical Chemistry Laboratory Parameters Derived from Normal Nigerian Adults. PLoS ONE, 9, e93919. http://dx.doi.org/10.1371/journal.pone.0093919

[15] Burgess, D.C., Gebski, V.J. and Keech, A.C. (2003) Baseline Data in Clinical Trials. Medical Journal of Australia, 179, 105-107.

[16] Akani, C.I., Erhabor, O., Opurum, H., et al. (2005) HIV Sero-Discordance among Nigerian Couples: Challenges and Controversies. Nigeria Medical Practitioner, 48, 62-66.

[17] Ruzagira, E., Wandiembe, S., Abaasa, A., et al. (2011) Prevalence and Incidence of HIV in a Rural Community-Based HIV Vaccine Preparedness Cohort in Masaka, Uganda. PLoS ONE, 6, e20684. http://dx.doi.org/10.1371/journal.pone.0020684

[18] Ige, K. and Nwachukwu, C. (2008) Health Care Seeking Behaviour among Market Traders in Ibarapa Central Local Government, Nigeria. The Internet Journal of Health, 9. http://ispub.com/IJGG/5/2/5831

[19] Agbogidi, J. and Azodo, C. (2009) Experiences of the Elderly Utilizing Healthcare Services in Edo State. The Internet Journal of Geriatrics and Gerontology, 5. http://ispub.com/IJH/9/2/9674

[20] Gyoh, S. (2011) Doctors and the Truth. African Health, 34, 5. 
[21] Sekoni, A.O., Odukoya, O.O., Onajole, A.T. and Odeyemi, K.A. (2013) Sexually Transmitted Infections: Prevalence, Knowledge and Treatment Practices among Female Sex Workers in a Cosmopolitan City in Nigeria. African Journal of Reproductive Health, 17, 94-102.

[22] Baltazar, R.M., et al. (2005) Prevalence of Sexually Transmitted Infections and Associated Risk Factors among Female Commercial Sex Workers in Cuantha, Morclos. Ginecología y Obstetricia de México, 73, 36-47.

[23] Balogun, M.O. and Owoaje, E.T. (2007) Work Conditions and Health Problems of Female Traders in Ibadan, Nigeria. African Journal of Medicine and Medical Sciences, 36, 57-63.

[24] Okechukwu, S.O., Okpechi, I., Chukwuonye, I.I., et al. (2012) Blood Pressure, Prevalence of Hypertension and Hypertension Related Complications in Nigerian Africans: A Review. World Journal of Cardiology, 4, 327-340. http://dx.doi.org/10.4330/wjc.v4.i12.327

[25] Pirraglia, P.A., Bishop, D., Herman, D.S., et al. (2005) Caregiver Burden and Depression among Informal Caregivers of HIV-Infected Individuals. Journal of General Internal Medicine, 20, 510-514. http://dx.doi.org/10.1111/j.1525-1497.2005.0073.x

[26] Player, M.S. and Peterson, L.E. (2011) Anxiety Disorders, Hypertension, and Cardiovascular Risk: A Review. International Journal of Psychiatry in Medicine, 41, 365-377. http://dx.doi.org/10.2190/PM.41.4.f

[27] Damulak, O. and Damen, J. (2012) Diagnostic Outcome of Bone Marrow Aspiration in a New Centre in Nigeria. Global Advanced Journal of Medicine and Medical Sciences, 1, 166-171.

[28] Chen, S.C., Yeh, J.J., Chang, M.H., et al. (2010) Gender Difference of Alanine Aminotransferase Elevation May Be Associated with Higher Hemoglobin Levels among Male Adolescents. PLoS ONE, 5, e13269. http://dx.doi.org/10.1371/journal.pone.0013269

[29] Song, H.R., Yun, K.E. and Park, H.S. (2008) Relation between Alanine Aminotransferase Concentrations and Visceral fat Accumulation among Nondiabetic Overweight Korean Women. The American Journal of Clinical Nutrition, 88, 16-21. 